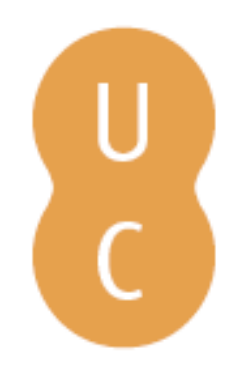

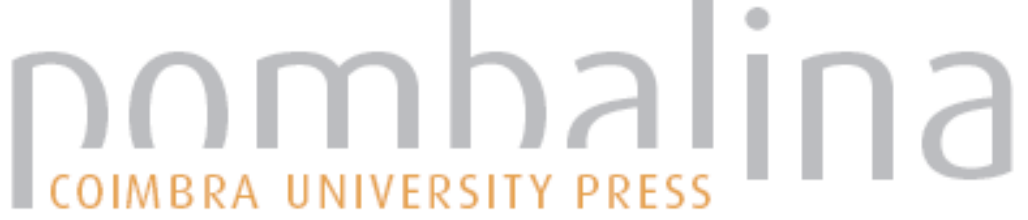

\section{A gestão de regimes complexos na ordem internacional contemporânea}

Autor(es): $\quad$ Moreno, Natália de Almeida

Publicado por: Imprensa da Universidade de Coimbra

URL

persistente: URI:http://hdl.handle.net/10316.2/47429

DOI: $\quad$ DOl:https://doi.org/10.14195/978-989-26-1524-0_5

Accessed : $\quad$ 26-Apr-2023 09:05:52

A navegação consulta e descarregamento dos títulos inseridos nas Bibliotecas Digitais UC Digitalis, UC Pombalina e UC Impactum, pressupõem a aceitação plena e sem reservas dos Termos e Condições de Uso destas Bibliotecas Digitais, disponíveis em https://digitalis.uc.pt/pt-pt/termos.

Conforme exposto nos referidos Termos e Condições de Uso, o descarregamento de títulos de acesso restrito requer uma licença válida de autorização devendo o utilizador aceder ao(s) documento(s) a partir de um endereço de IP da instituição detentora da supramencionada licença.

Ao utilizador é apenas permitido o descarregamento para uso pessoal, pelo que o emprego do(s) título(s) descarregado(s) para outro fim, designadamente comercial, carece de autorização do respetivo autor ou editor da obra.

Na medida em que todas as obras da UC Digitalis se encontram protegidas pelo Código do Direito de Autor e Direitos Conexos e demais legislação aplicável, toda a cópia, parcial ou total, deste documento, nos casos em que é legalmente admitida, deverá conter ou fazer-se acompanhar por este aviso. 
JOSÉ MANUEL PUREZA JOSÉ JUSTE RUIZ (COORDS.)
IMPRENSA DA

UNIVERSIDADE

DE COIMBRA

COIMBRA

UNIVERSITY

PRESS
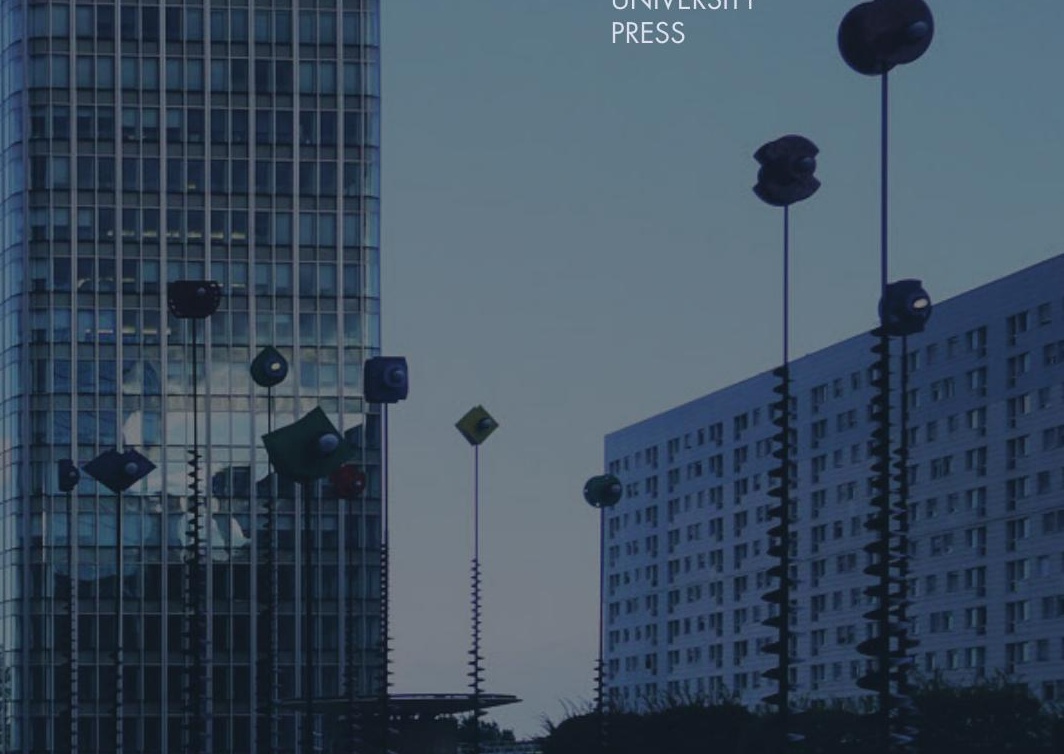

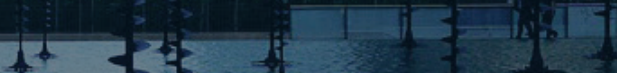

OS ESTADOS

EA ORDEM

INTERNACIONAL

CONTEMPORANEA

ATAS DO V ENCONTRO LUSO-ESPANHOL DE Professores de Direito internacional e RELAÇÕES INTERNACIONAIS 


\section{A GESTÃO DE REGIMES COMPLEXOS NA ORDEM I NTERNACIONAL CONTEMPORÂN EA 1}

\section{Natália de Almeida Moreno}

\section{Introdução}

O presente trabalho pretende examinar os regimes jurídicos complexos assomados no cenário internacional contemporâneo, apresentando os mecanismos potencialmente hábeis a gerir as dificuldades e conflitos que daí emergem.

Como tarefa primeira para o alcance destes fins, estudaremos sinteticamente as mudanças do Direito Internacional Público nas últimas décadas; em um segundo momento, elucidaremos em que consistem os regimes complexos para apresentar, ao fim, as propostas nos parecem hábeis a geri-los de modo a articular as múltiplas tendências e interesses que se expressam internacionalmente.

${ }^{1} \mathrm{O}$ presente trabalho deriva da pesquisa realizada no Seminário "A Realização do Direito pelas Jurisdições Internacionais" do Curso de Doutoramento em Direito Público da Faculdade de Direito da Universidade de Coimbra, cujos resultados foram em sua integralidade publicados em Moreno, Natália de Almeida (2014), "Regimes Complexos no Cenário Internacional Contemporâneo", Revista de Direito Constitucional e Internacional, 88, 275-316. 


\section{A Ordem Internacional Contemporâneo}

O Direito Internacional Público modificou-se substancialmente nas últimas décadas. O esmorecimento do Modelo de Vestefália a partir do fim da Segunda Grande Guerra acelerou-se em definitivo no período que se seguiu à queda do Muro de Berlim, deixando a cena internacional órfã de uma nova ordem-paradigma (Valaskakis, 2001: 45).

O que assistimos, na atualidade, é um espaço internacional em processo de (rápida e dinâmica) transformação, sem que tenha havido ainda o assentamento dos novos horizontes e bases que irão ditar e estruturar a ordem jurídico-internacional na contemporaneidade.

Se as trocas - de bens, valores, informações, culturas e experiências - entre diferentes povos já há muito ocorriam no cenário global, não há dúvidas, porém, que as "interacções transnacionais" (Santos, 2002) tomaram vulto e características especiais a partir das duas últimas décadas do século XX com a emergência do fenômeno da globalização.

A distribuição dos processos produtivos e a integração dos mercados em uma perspectiva global propiciaram o crescimento, em número e importância, das trocas e alianças supranacionais e, mais que isso, a presença de atores não-governamentais no plano internacional, atuando autonomamente a ou para além das fronteiras e interesses dos Estados-nação.

Ademais, a deslocalização das trocas do plano nacional para um mercado global passou a demandar uma regulação cada vez mais intensa das "regras do jogo" pela via internacional, multiplicando-se exponencialmente o número de normas e instituições supranacionais em diferentes matérias e setores. E, para além da produção normativa "oficial", isto é, editada com base nos processos negociais e contratuais tradicionais e ínsitos ao modelo vestefaliano, intensificou-se uma produção normativa "paralela", não-governamental, com o estabelecimento de parâmetros técnicos e de conduta por fontes puramente privadas ou mistas (público-privadas), denotando 
a ampliação da liberdade e capacidade de auto-conformação dos agentes não-governamentais em espaços desafetados às jurisdições estaduais e em campos cujo consenso internacional para formatação por meio das vias tradicionais está ainda longe de ser alcançado.

Em acréscimo, face ao extravasamento dos limites da jurisdição do Estado-nação das condutas e agentes de alcance global e à constatação de que há riscos e problemas que não podem ser limitados nem quanto ao tempo, nem quanto ao espaço ${ }^{2}$, assiste-se à flexibilização da autonomia ${ }^{3}$ dos Estados nacionais e à consequente descentralização dos outrora monopolizados poderes decisórios estatais, ao mesmo tempo em que se constata o aguçamento da interdependência dos diversos atores ao redor do globo, pois há hoje uma gama de questões que demandam ações e soluções coordenadas, transfronteiriças ${ }^{4}$, compelindo os Estados a "desenhar e implementar respostas conjuntas" (Finn, 2010: 550), visto já não mais possuírem meios de enfrentar, sozinhos, tais problemas.

A ruptura da centralidade dos Estados na protagonização do cenário internacional e a flexibilização da soberania e limites nacionais não significam, contudo, que tenha sido o Estado-nacional soberano substituído plenamente em suas funções por organizações internacionais ou por entidades privadas transnacionais; tampouco que o Direito tenha renunciado espaço ao Mercado.

$\mathrm{Na}$ realidade, todas estas grandes transformações vieram acompanhadas de importantes contra-tendências, como a revalorização da seara local, de modos de fazer político altamente cooperativos e participativos e o crescimento de movimentos, de expressão local e

\footnotetext{
${ }^{2}$ Beck, Ulrich (2001), La Sociedad del Riesgo Global. Siglo Veintiuno de España Editores.

3 Mathews, Jessica T. (1997), "Power Shift", Foreign Affairs, 76(1), 50-66.

${ }^{4}$ Benner, Thorsten et al (2005), "Shaping Globalization. The role of global public policy networks", in Bertelsmann Foundation (ed.), Transparency: A Basis for Responsibility and Cooperation. Gütersloh: Bertelsmann Foundation Publishers, 67-86.
} 
global, de resistência ${ }^{5}$ cultural, econômica e política, que englobam fins redistributivos diversos voltados a corrigir as graves assimetrias que a alocação de recursos ao nível global tem o condão de gerar.

Por isso, multiplicaram-se e pluralizaram-se vigorosamente os interesses manifestados diretamente na sede internacional, decorrendo daí o empoderamento de importantes grupos não-governamentais e do próprio indivíduo no espaço transnacional.

Sucede que todos estes interesses e o volumoso corpo de normas internacionais não estão sujeitos a um fórum único, a um centro a partir do qual é produzido, dirigido, sistematizado, interpretado, aplicado e monitorizado o Direito.

Ao extenuar fronteiras e criar novas escalas e estruturas de relacionamento e processos comunicativos e produtivos, estas transformações turvam os limites de responsabilidades e competências, dissipando poder (entre Estados, OIs, empresas, NGOs, indivíduos, associações) e encolhendo os espaços de exercício e a intensidade das formas tradicionais de autoridade (Slaughter, 2004), produzindo, em síntese, como efeitos últimos, a fragmentariedade e a descentralização.

Por isso, os processos formativos e implementadores de políticas públicas de origem e/ou repercussão internacional complexificaram-se substancialmente, fazendo assomar hodiernamente regimes jurídicos em que competências, regras e princípios se sobrepõem e conflituam intensamente.

\section{Regimes complexos}

As transformações sofridas pelo Direito Internacional Público atual culminam em que diversas áreas que antes eram consideradas

\footnotetext{
5 Este contra-movimento é o que Santos (2002) nomeia cosmopolitismo, referindo-se à "organização transnacional da resistência de Estados-nação, regiões, classes ou grupos sociais vitimizados pelas trocas desiguais de que se alimentam os localismos globalizados e os globalismos localizados".
} 
distintas e segmentáveis (direitos humanos, comércio internacional, direito ambiental, etc.) e se encontravam reguladas por centros de poder bem definidos (Estados e/ou organizações internacionais) não mais podem ser "analiticamente separadas" (Emadi-Coffin, 2002: 10), tampouco se submeter a divisões claras de competências e de poder, tendo em vista a configuração de vastas zonas de interseção e interação necessárias entre as matérias e as diferentes esferas reguladoras - públicas, privadas ou mistas, de âmbito local, nacional, regional ou internacional.

É diante deste quadro que Raustiala e Victor (2004: 279) identificaram a formação em âmbito internacional de regimes jurídicos complexos, particularizados como "uma gama de instituições parcialmente sobrepostas e não hierarquicamente organizadas governando uma particular área de interesse".

Trata-se de regimes em que diferentes instituições e regimes jurídicos setoriais ("regimes elementares") são criados e mantidos de forma autônoma, porém o seu desenvolvimento, performance e implementação denotam importantes pontos de interligação $e$ sobreposição quanto a uma determinada matéria, atividade ou área de interesse regulatório, atraindo, por esta razão, atenção especial para as externalidades (positivas ou negativas) e interconexões que tais interações têm o potencial de gerar.

Estes regimes jurídicos setoriais (regimes elementares) são as regras e princípios insculpidos em tratados internacionais, costumes, regulamentos expedidos por OIs, códigos de conduta, procedimentos e decisões a conformar uma matéria a nível internacional.

Individualmente considerados, porque circunscritos a uma específica matéria de interesse (v.g., a liberdade de comércio internacional, a proteção de espécies marinhas em extinção, standards de qualidade alimentar) e criados de forma independente e fragmentada (v.g., criação e estabelecimento de poderes e competências da OMC em 1994, criação e entrada em vigor do sistema CITES das Nações Unidas em 
1975, compilação na norma ISO 22000 dos parâmetros de gestão de segurança alimentar), não parecem colocar quaisquer problemas e dificuldades sistêmicas, regendo-se natural e regularmente pelas normas, procedimentos e precedentes decisórios que lhes são próprios.

$\mathrm{O}$ problema e as dificuldades exsurgem quando diferentes regimes elementares, funcionando concomitantemente, apresentam pontos de interação e justaposição no âmbito de uma matéria comum, fazendo surgir choques entre os princípios gerais, normas, regras, procedimentos e decisões que compõem individualmente cada uma de suas partes.

Os regimes complexos, portanto, são essencialmente sistêmicos ${ }^{6}$, assomando da combinação de organizações e regimes jurídicos que, mostrando-se ou não interconectados à primeira vista, se conformam, afetam e contradizem mutuamente.

Não são, porém, quaisquer tipos e graus de relacionamentos entre regimes elementares que dão ensejo à formação de regimes complexos. Orsini, Morin e Young (2013b: 29-30) elucidam que as partes componentes de um regime complexo, para o caracterizarem, devem relacionar-se em três principais aspectos: (i) disciplinar, total ou parcialmente, ao mesmo tempo e num mesmo patamar jurídico-normativo ${ }^{7}$, uma matéria ou atividade comum; (ii) submeter, total ou parcialmente, os mesmos agentes (Estados, OIs, empresas, ONGs, indivíduos) às suas regras e princípios, procedimentos e decisões; e (iii) interagirem entre si em diferentes níveis - subjetivo, material, normativo e operativo -, gerando, por estes motivos, desafios para o sistema.

\footnotetext{
${ }^{6}$ Gehring, Thomas et al. (2010), Division of Labor within Institutional Complexes and the Evolution of Interlocking Structures of International Governance: The Complex of Trade and the Environment. European International Studies Association, Stockholm Conference.

7 É de se salientar que, embora estejamos aqui a tratar dos regimes complexos no plano internacional, as redes normativas de que fazem parte estendem-se igualmente às jurisdições regionais, nacionais e locais, falando-se, assim, de uma regulação multinível e de uma nova geografia da governança.
} 
A complexidade de um (macro-)regime exsurge, então, em primeiro plano, da pluralidade de diplomas, objetivos e interesses relacionados às diversas matérias dialogadas e decididas a nível internacional.

A ausência de um centro conformador e emanador de parâmetros jurídicos, somado aos liames materiais tênues integradores do sistema internacional, fazem com que o consenso necessário (ou a aparência de consenso) ínsito aos regimes jurídicos nacionais seja muitas vezes encarado como "despiciendo" (Raustiala et al., 2004: 280) no plano internacional, dada a maior liberdade dos atores para criarem fóruns alternativos, para se auto-conformarem e transformarem os seus interesses em nichos institucionais autonomizados, sem que, em contrapartida, haja mudanças e evoluções recíprocas nas "forças motrizes subjacentes" (Raustiala et al., 2004: 296) à formação normativa para acompanhar o processo constitutivo de políticas.

Há, portanto, uma grande dispersão de valores, objetivos e interesses, que acaba por se traduzir na multiplicidade de disciplinas jurídicas para uma mesma matéria, potenciando, à evidência, fenômenos problemáticos para o sistema, como o comportamento oportunista de atores mediante a prática de forum shopping, o surgimento de turf battles e o crescimento exponencial de antinomias jurídicas.

O cenário agrava-se pela constatação de que tais sobreposições dão-se tanto sob uma perspectiva intra-regime (i.e., no seio de regimes afetos a um mesmo assunto - ambiente, comércio, energia), quanto no relacionamento dos regimes entre si (i.e., entre regimes elementares diferentes - comércio e meio ambiente, energia e mercados financeiros, etc.).

À evidência, nestes cenários, o grau de complexidade e o potencial das dificuldades é diretamente proporcional ao número de atores que participam e integram concomitantemente os diferentes regimes em interseção.

Fossem claras as opções dos sujeitos de direito internacional por uns ou outros regimes, a situação se desataria facilmente através 
do adimplemento, por um determinado grupo de atores, do (sub-) sistema $\mathrm{X}$, por outro grupo do sistema $\mathrm{Y}$ e assim por diante.

Sucede que os mesmos atores participam de, dialogam em e estão sujeitos a regimes elementares distintos, seja pela pluralidade de representantes enviados à esfera global, seja pela democratização das instâncias decisórias internacionais.

$\mathrm{Na}$ medida em que na seara internacional as decisões tomadas em um nicho não se estendem a nem encobrem automaticamente (Orsini et al., 2013b: 29) regimes outros (paralelos ou claramente sobrepostos), a participação de diversos atores em regimes elementares afetos a uma mesma matéria é não só comum, como manifestamente adversa à coesão do sistema.

Daí o último elemento formativo de regimes complexos ser a interação entre regimes elementares nos níveis subjetivo, material, normativo e operativo.

Subjetivo relativamente aos atores que interagem na negociação, formação e implementação dos diferentes regimes; material, no que concerne às matérias reguladas, que podem ser tanto circunscritas a uma única atividade "guarda-chuva" (ambiente, energia, comércio), quanto interdisciplinares; normativo no sentido de as suas normas, princípios, regras e decisões se interrelacionarem, conflituando e confrontando-se mutuamente; e, por fim, operativo por motivo dos impactos e efeitos - negativos (v.g., conflitos, inconsistências, antinomias) ou positivos (v.g., cooperação, avanços reforçados, respeito às particulares locais) - que a operação de um regime (o seu cumprimento, implementação) gera a outro e ao sistema como um todo (Orsini et al., 2013b: 31).

À vista destas interações, torna-se claro o grande potencial dos regimes complexos de colocarem em causa a ordem e a coesão do Direito Internacional, demandando respostas e desenvolvimentos coerentes e coordenados para todo o conjunto, de modo a evitar ou, no mínimo, mitigar os resultados deletérios que objetivos e políticas fragmentadas e desalinhadas podem gerar. 


\section{Que gestão possível?}

Os regimes complexos se situam no meio do caminho entre regimes totalmente fragmentados, sem coesão e coordenação direta entre si, e regimes normativos totalmente integrados, passíveis de resolverem eventuais antinomias e conflitos mediante parâmetros e normas pré-estabelecidos intra-sistemicamente.

Não são - nem podem ser tratados como - "ilhas regulatórias" decompostas e isoladas, mostrando-se necessário conhecer e gerir os pontos de interseção que os conectam; tampouco se mostram como regimes completos e hierarquizados, em que no seu próprio bojo estão fixadas divisões claras de competências e funções e regras capazes de regularem o desenvolvimento e a coesão do sistema em si mesmo.

Como, então, garantir a coexistência entre as diferentes instituições e normas que os compõem?

Gehring e Faude (2010), pautando-se em uma "ecologia institucional", defendem que a acomodação dos diferentes regimes elementares formadores de regimes complexos dá-se naturalmente, mediante uma seleção natural das instituições e dos regimes normativos que melhor lograrem representar os interesses da comunidade internacional.

Também Orsini e Morin (2013a) argumentam que, ao longo da vida de um complexo, há uma acomodação natural das instituições e uma evolução gradual do "ciclo de vida" do complexo até a integração, em que o regime se apresenta unificado, atingindo um nível ótimo de estabilização interna e cooperação ${ }^{8}$.

Embora desejemos que a evolução natural dos regimes complexos se encaminhe para a ordem e a coesão, pensamos que a resposta aos problemas que suscitam não pode ser simplesmente aguardar

\footnotetext{
${ }^{8}$ Ainda sobre a tipologia das interações passíveis de surgirem entre instituições e instrumentos regulatórios, v. Gunningham, Neil et al (1998), Smart Regulation: Designing Environmental Policy. Oxford: Clarendon Press Oxford, 126-132.
} 
por uma eventual coesão natural entre as instituições e regimes elementares que os compõem.

É preciso desenvolver parâmetros adequados de gestão que mitiguem antinomias, lacunas e conflitos, tendo em mente, concomitantemente, o profundo grau de conexão e interdependência entre os diferentes regimes elementares e a horizontalidade em que tais trocas e interações têm lugar.

Uma vez que cada um dos regimes elementares ou dos atores participantes do complexo normativo não podem atingir nem resolver, sozinhos, os objetivos e problemas últimos do sistema inteiramente considerado, a sua gestão há-de pautar-se menos em uma competição intersubjetiva e interinstitucional e mais na cooperação e no diálogo entre os diferentes atores.

A formação de esquemas organizativos hábeis a incentivar e garantir a coordenação e cooperação no âmbito dos regimes complexos afigura-se, então, no nosso entender, fundamental.

Colocar as partes interessadas em diálogo permite uma aprendizagem recíproca e abrangente dos interesses, propostas e experiências apresentadas pelos diversos atores, ao mesmo tempo em que estimula uma co-evolução gradual e convergente das percepções e decisões manifestadas.

Os regimes complexos, portanto, hão-de ser conectados entre si, permitindo a comunicação e, a partir daí, a co-construção e o co-monitoramento entre os diversos regimes elementares que os compõem (e respectivos atores interessados e instituições). Para tanto, uma organização em rede a englobar e criar canais comunicativos e de troca (de informações, entendimentos, evoluções, experiencias, resultados) entre os principais regimes parece-nos indispensável, de modo que cada regime elementar funcione como um dos diversos núcleos a formar o todo sistémico e cada "ponte de comunicação" a ligar os diferentes regimes elementares ligue-se a outras pontes, formando assim diversos "nós", pontos de interseção e links entre uns e outros. 
Desse modo, os diversos regimes elementares não se afiguram nem isolados, nem verticalmente integrados, acomodando-se mediante interconexões e interações diversas sem itinerários pré-fixados e sem parâmetros fechados e estáticos de comunicação.

Em particular para os regimes complexos, uma ação concertada e coordenada organizada em rede é indispensável à luz de sua essência sistêmica, a impor que, para além da gestão de cada um dos regimes elementares individualmente considerados, dê-se atenção às interações, falhas e sinergias entre eles, garantindo a estabilidade e coesão do sistema como um todo.

Isto importa, ainda, porque a organização horizontalizada destes regimes, desvestida de parâmetros pré-fixados e estáticos de orientação e organização, põe em causa a suficiência e a aptidão das fórmulas tradicionais de resolução de antinomias e sobreposições normativas para responder aos desafios que emergem das interações presentes nestes sistemas complexos.

Sinteticamente, a compreensão dos sistemas jurídicos como fechados, completos e hierarquicamente (piramidalmente) organizados impunha que as aparentes antinomias se resolvessem intra-sistemicamente, mediante o estabelecimento de regras pré-fixadas e gerais aplicáveis à generalidade das interações ente normas, criando-se parâmetros escalonados e consecutivos pautados em critérios de habilitações constitucionais, hierarquia, especialidade e temporalidade.

Este esquema, se já não se mostra totalmente compatível com as transformações do Direito no âmbito nacional, no plano internacional nunca foi pacificamente aplicado.

Os autores que pretenderam transportar tais parâmetros para o ordenamento internacional ${ }^{9}$ defrontaram-se com dificuldades advindas da especialidade organizacional e formativa do Direito

9 V. por todos Pauwelyn, Joost (2009), Conflict of Norms in Public International Law. Cambridge: Cambridge University Press. 
Internacional Público, chegando a um resultado, senão desacertado, ao menos insuficiente.

A inviabilidade de institucionalização de um governo global único a alocar competências e organizar os diferentes atores internacionais, somada às dificuldades de assentamento de parâmetros meta-normativos universais hábeis a parametrizar e constranger a produção e aplicação de regras e princípios no plano internacional impedem que as lógicas para solução de antinomias estruturadas para ordenamentos nacionais sejam extravasadas para o plano internacional.

Efetivamente, o princípio de igualdade soberana dos Estados implica, de um lado, a liberdade de atuação e de escolha dos Estados em se submeterem a parâmetros jurídico-normativos internacionais (auto-vinculação); e, de outro lado, as (hoje já mitigadas) não-hierarquização e neutralidade valorativa das normas de direito internacional, conferindo-se igual peso e estima às diferentes normas a que decidiram se vincular.

Daí que as características ínsitas ao Direito Internacional, de ontem e de hoje, colocaram sempre dificuldades à transposição das tradicionais regras de solução de antinomias para o plano supra-nacional, o que se torna ainda mais patente à vista da formação de regimes complexos.

Em primeiro lugar porque, como temos exposto, inexiste no cenário global contemporâneo uma divisão clara de competências e funções; pelo contrário, assistimos a uma diversificação não só das arenas em que são debatidas, formadas e interpretadas as normas internacionais, como dos próprios tipos de atores e instituições incumbidos de negociar, criar e levar a efeito normas de Direito Internacional.

Além disso, nos sistemas normativos complexos, não há hierarquias fixas e imutáveis tal como nos sistemas piramidais.

Em segundo lugar, cada um dos regimes elementares coloca-se a regular de forma especial e específica os seus objetos materiais, não sendo possível, por exemplo, decidir eventuais antinomias 
entre o regime do comércio e o regime ambiental internacionais com base em critérios de especialidade, pois são ambos especiais relativamente às relações e atividades que se põem a regular.

Tampouco o critério da temporalidade é passível de ser aplicado sem prévias ponderações e análises. Conquanto seja evidente que as evoluções da técnica, da ciência, das sociedades e seus respectivos valores e ideologias irão marcar a produção e interpretação normativas, fazendo-as igualmente evoluir para responderem às incrementais necessidades da realidade, não nos parece ser sempre o caso de um diploma internacional posteriormente acordado haver de elidir as normas anteriormente fixadas acerca de uma matéria.

Assim é porque as fontes normativas do direito internacional possuem graus de vinculatividade e efetividade diversos, não se podendo admitir, por exemplo, que um diploma que preveja princípios e regras gerais, com um reduzido grau operativo, possa substituir um outro diploma anterior, sobre a mesma matéria, que contenha obrigações claras, determinadas e específicas sobre a idêntica questão já amplamente reconhecidas e aplicadas sobre a matéria.

Ademais, o fato de uma pluralidade de diplomas incompatíveis entre si serem negociados e celebrados no plano internacional denota as múltiplas tendências e interesses que orbitam a produção normativa, não se podendo extrair como conclusão que as tendências mais recentemente manifestadas sejam as que devam ou mereçam prevalecer.

Não é despiciendo anotar, em acréscimo, que a lógica do direito internacional de absorção e efetivação incremental transforma o tempo em um importante aliado do assentamento e concretização normativos, sendo certo que a maioria das regras, princípios, procedimentos e decisões depende de reiterada e estável observação e aplicação por parte dos destinatários das normas para se tornarem verdadeiramente relevantes e efetivas.

Por tudo isso, resolver as dificuldades assomadas da interação entre normas não pode passar pela aplicação mecânica de um 
critério temporal (ou de qualquer outro critério fixo e imponderável), merecendo reflexão, no nosso entendimento, (i) o grau de efetividade e vinculatividade das normas em conflito; (ii) o grau de proteção do bem jurídico tutelado promovido pelas normas ${ }^{10}$; e (iii) os impactos que as possíveis soluções irão causar ao sistema inteiramente considerado.

Não por acaso que Castells, ao discorrer sobre a generalidade das redes (normativas ou não), acentua que

os nós podem ter maior ou menos relevância para o conjunto da rede: aumentam sua importância quando absorvem mais informação relevante e a processam mais eficientemente. A importância relativa de um nó não provém de suas características especiais, mas sim de sua capacidade para contribuir para os objetivos da rede (Castells, $2011: 27$ ).

Logo, não serão as "características especiais" (de hierarquia, de especialidade, de temporalidade) de cada um dos regimes elementares que irão decidir a sua importância e a prevalência no caso de conflitos, mas a sua "capacidade para contribuir para os objetivos da rede", isto é, os objetivos do sistema jurídico internacional.

Precisamente nessa linha, a teoria do "diálogo das fontes" de Jayme (1995) volta-se a estabelecer novos parâmetros para análise e solução de interações normativas para além dos critérios tradicionais da hierarquia, especialidade e temporalidade, apresentando-se mais consentânea com um direito (internacional) pós-moderno plural, difuso e amplamente calcado em princípios que superam a lógica de "tudo ou nada" das regras jurídicas.

${ }^{10}$ A ponderação à luz do princípio do nível mais elevado de proteção para solução de conflitos complexos foi-nos sugerida pela Prof ${ }^{a}$. Doutora Alexandra Aragão, a quem oportunamente agradecemos. 
A ideia central de Jayme (2003: 120) repousa em que a diversidade e a pluralidade são, antes de um mal, uma virtude a ser explorada e desenvolvida, atingindo-se uma solução não através do monólogo (a supressão de uma norma por outra), mas por diálogo, uma "coordenação sistemática" entre os diferentes atores envolvidos, os valores em questão e, sobretudo, entre as diferentes fontes normativas: ao invés da economia ou do meio ambiente, o desenvolvimento sustentado, por exemplo.

Estes diálogos, na sistematização de Marques (2012: 32), se fariam presentes em três principais níveis: 1) o diálogo sistemático de coerência: verificando a aplicação conjunta e simultânea de duas leis, uma lei deve servir de base conceitual para a outra, inclusive através do reconhecimento de interconexões e contribuições que o direito geral pode prestar ao direito especial e vice-versa; 2) o diálogo da complementaridade e subsidiariedade: uma norma pode incidir de forma complementar ou subsidiária a outra, integrando eventuais lacunas e orientando interpretações a um resultado sistemático; 3) o diálogo de coordenação e adaptação sistemática ou de influências recíprocas: redefinir ou reinterpretar o campo de aplicação ou o sentido de uma norma para que se adapte às novas conformações do sistema e às novas conformações da realidade.

O pano de fundo, o elo de coesão, de tais diálogos seriam, nessa vertente, os valores fundamentais do sistema jurídico, que, no plano internacional, vêm gradual, mas crescentemente, evoluindo, na aguçada imagem de Pureza (2002), de um sistema de Estados para um sistema da Humanidade, com a formação de importantes núcleos de convergência pautados sobretudo nas normas de ius cogens, nas obrigações internacionais erga omnes e nos princípios gerais e fundamentais de Direito Internacional - uma "Constituição global" em sentido material.

Portanto, não é possível ignorar as complexidades ínsitas ao sistema jurídico internacional, ultrapassando-as com a aplicação de modelos desenvolvidos para gestão de cenários simples, lineares e estáticos. 
Pilotar regimes complexos depende, ao revés, e necessariamente, de identificar, reconhecer, entender e adaptar-se às fontes e consequências da complexidade.

A gestão destes regimes, no nosso entender, então, há-de passar pela governança em rede capaz de promover a colaboração, cooperação e complementaridade entre os diversos atores e regimes que integram os sistemas complexos, criando um ambiente passível de absorver as dinâmicas e complexidades do sistema e de acomodar os interesses, valores e objetivos plúrimos do cenário internacional contemporâneo, contribuindo, em última instancia, para a coesão do sistema.

A gestão pela via da governança visa coordenar forças, combinando os diferentes e difusos "esforços governativos" (Kooiman, 2003) existentes - públicos, privados ou mistos, globais, regionais, nacionais ou locais, da hard à sof law e natureza multidisciplinar.

Trata-se de responder à diversidade, dinâmica e complexidade do mundo contemporâneo através do reconhecimento de que as respostas na atualidade são mais eficazmente construídas pela agregação de experiências, capacidades, conhecimento e informação que nenhum dos atores, nem os poderes públicos, pode melhor prover sozinho (Ost et al., 2002: 11); que a dificuldade do assentamento, análise e resolução dos problemas que hoje se colocam não permite "axiomas a priori" (Ost et al., 2002: 11), respostas unas, certas, imutáveis, mas depende, ao revés, de uma aprendizagem e conformação contínua e conjunta dos interessados e instituições envolvidos (Paquet, 2001: 197); enfim, que a justiça, antes de ser revelada por valores hierarquizados fixados na lei, "é apreendida hoje em termos de escalas de interesse e equilíbrio tão diversas como variáveis" (Ost et al., 2002: 11), impondo ajustes mútuos e diálogos calcados em experiências contextualizadas, debatidas e disseminadas ao longo da cadeia de interessados. 
A organização em rede permite potencializar tais processos e objetivos, dotando a governança de um caráter mais flexível e descentralizado hábil a lidar com os diferentes atores em "diferentes posições e níveis na sociedade" (Kooiman et al., 2008: 3), reforçando a sua habilidade comunicativa através da formação de pontes e links entre eles a partir dos quais tais informações, capacidades, experiências, conhecimentos e aprendizagens podem ser disseminadas, analisadas em conjunto e proverem uma base de partida comum às formulações e alterações de políticas e ao acompanhamento e controle mútuo por parte dos componentes da rede.

$\mathrm{Na}$ ausência de um centro claro de decisão e formação de políticas e normas, tal como ocorre no plano internacional, a "independência de ação" (Ansell et al., 2012: 318) dos diferentes atores, instituições e interessados, para não inviabilizar a manutenção e o funcionamento regular do sistema, há-de ser conjugada com a coordenação entre eles, criando condições e incentivos para a formação de "processos orientados por objetivos" (Bruijn, 1997: 120), em que os fins e valores últimos do ordenamento funcionem, concomitantemente, como nortes e elos de coesão das políticas difusamente formuladas.

\section{Conclusões}

As novas fronteiras do direito internacional contemporâneo impõem o desenvolvimento de mecanismos inovadores que assumam e internalizem a sua complexidade e o dinamismo.

Para tanto, afigura-se-nos fundamental uma coordenação institucional organizada em rede, mediante a aplicação dos métodos mais flexíveis da governança em rede para resolução de antinomias e composição de interesses, promovendo o diálogo, a cooperação e a troca intersubjetivas e internormativas. 


\section{Referências}

Abbott, Kenneth W.; Snidal, Duncan (2009), "The Governance Triangle: Regulatory Standards Institutions and The Shadow of the State", in Mattli, Walter; Woods, Ngaire (eds.), The Politics of Global Regulation. Princeton University Press, 44-88.

Albrow, Martin (2001), "Society as Social Diversity: The Challenge for Governance in the Global Age", in OECD. Governance in the $21^{\text {st }}$ Century. Paris: OECD, 149-182.

Ansell, Chris; Sondorp, Egbert; Stevens, Robert Hartley (2012), "The Promise and Challenge of Global Network Governance: The Global Outbreak Alert and Response Network", Global Governance, 18, 317-337.

Ayres, Ian; Braithwaite, John (1995), Responsive Regulation - Transcending the Deregulation Debate. New York/Oxford: Oxford University Press.

Baldwin, Robert; Cave, Martin; Lodge, Martin (2012), Understanding Regulation: Theory, Strategy, and Practice. New York: Oxford university Press Inc. [2 ${ }^{\text {nd }}$. Ed].

Barry, Brian (2001), Culture and Equality: An Egalitarian Critique of Multiculturalism. Cambridge, MA: Harvard University Press.

Beck, Ulrich (1998), La Sociedad del Riesgo. Hacia una nueva modernidad. Barcelona: Ediciones Paidós Ibérica.

Beck, Ulrich (2001), La Sociedad del Riesgo Global. Siglo Veintiuno de España Editores.

Benhabib, Seyla (2002), The Claims of Culture: Equality and Diversity in the Global Era. Princeton: Princeton University Press.

Benner, Thorsten; Reinicke, Wolfgang H.; Witte, Jan Martin (2002), "Shaping Globalization. The role of global public policy networks", in Bertelsmann Foundation (ed.), Transparency: A Basis For Responsibility and Cooperation. Gütersloh: Bertelsmann Foundation Publishers.

Benner, Thorsten; Reinicke, Wolfgang H.; Witte, Jan Martin (2005), "Multisectoral Networks in Global Governance: Towards a Pluralistic System of Accountability", in Held, David; Koenig-Archibugi, Mathias (eds.), Global Governance and Public Accountability. Oxford: Blackwell Publishing, 67-86.

Bodansky, Daniel (1999), "The Legitimacy of International Governance: A Coming Challenge for International Environmental Law?", Scholarly Works, 443. Consultado a 13.06.2014 em: http://digitalcommons.law.uga.edu/fac_artchop/443.

Braithwaite, John (1999), "Accountability and Governance under the New Regulatory State”, Australian Journal of Public Administration, 58(1), 90-97.

Brändli, Christian (2012), "Book Review The New Global Rulers: The Privatization of Regulation in the World Economy by Büthe, Tim and Mattli Walter", Swiss Political Science Review, 18(4), 538-540.

Bruijn, J. A. de; ten Heuvelhof, E. F. (1997), "Instruments for network management", in Kickert, W. J. M. (ed.), Managing Complex Networks: Strategies for the Public Sector, London: Sage, 119-136.

Brül, Tanja (2006), "The privatization of governance systems. On the legitimacy of international environmental policy", in Benz, Arthur; Papadopoulos, Yannis (ed.), 
Governance and Democracy. Comparing national, European and international experiences. Routledge: New York, 228-251.

Calliess, Gralf-Peter (2010), "Transnational Law", CLPE Research Paper 35/2010. Osgoode Hall Law School, Comparative Research in Law \& Political Economy, 6(8). Consultado a 10.06.2014 em: http://ssrn.com/abstract $=1630348$.

Cassese, Sabino (2010), C'è un ordine nello spazio giuridico globale? Consultado a 10.06.2014 em http://www.irpa.eu/wp-content/uploads/2011/05/la-macchinaglobale-Lumsa-25-maggio.pdf

Cassese, Sabino; Casini, Lorenzo (2012), "Public Regulation of Global Indicators", in Davis, Kevin; Fisher, Angelina; Kingsbury, Benedict; Merry, Sally Engle (eds.), Governance by Indicators. Global Power through Quantification and Rankings. Oxford/New York: Oxford University Press, 465-474.

Castells, Manuel (2011), La Sociedad Red: una visión global [trad. Francisco Muñoz de Bustillo]. Madrid: Alianza Editorial [1 ed., 2 reimpressão].

Dunsire, Andrew (1994), "Modes of Government", in. Kooiman, Jan. (ed.), Modern Governance. New Government - Society Interactions. London: SAGE Publications, 21-34.

Emadi-Coffin, Barbara (2002), Rethinking International Organisation: Deregulation and Global Governance. Oxfordshire: Taylor \& Francis Ltd.

Esty, Daniel C. (2006), "Good Governance at the Supranational Scale: Globalizing Administrative Law", Yale Law Journal, 115, 1490-1562.

Ferrarese, Maria Rosaria (2010), La Governance tra Politica e Diritto. Bologna: Società Editrice il Mulino.

Finn, Devin (2010), "International Authority, Deliberative Legitimacy, and the Responsibilities of States", Global Governance, 16, 549-558.

Freeman, Jody (2000), "The Private Role in Public Governance", New York University Law Review, 75, 543-674.

Fukuyama, Francis (2013), "What is Governance?", Governance: An International Journal of Policy, Administration, and Institutions, 26 (3), 347-368.

Gehring, Thomas; Faude, Benjamin (2010), Division of Labor within Institutional Complexes and the Evolution of Interlocking Structures of International Governance: The Complex of Trade and the Environment. European International Studies Association, Stockholm Conference. Consultado a 07.06.2014 em: http:// www.eisa-net.org/be-bruga/eisa/files/events/stockholm/Gehring-Faude-Divisionof-Labour-within-Institutional\%20Complexes.pdf.

Gehring, Thomas; Faude, Benjamin (2013), "The Dynamics of Regime Complexes: Microfoundations and Systemic Effects", Global Governance, 19, 119-130.

Giddens, Anthony (1991), As Conseqüências da Modernidade [trad. de Raul Fiker]. São Paulo: Editora UNESP, 1991.

Grupo de Lisboa (1994), Limites à Competição. Europa-America.

Gunningham, Neil; Grabosky, Peter; Sinclair, Darren (1998), Smart Regulation: Designing Environmental Policy. Oxford: Clarendon Press Oxford.

Herranz Jr., Joaquín (2008), "The Multisectoral Trilemma of Network Management", Journal of Public Administration Research and Theory, 18(1), 1-31. 
Innerarity, Daniel (2011), o Futuro e os seus Inimigos. Uma defesa da esperança politica. Alfragide: Teorema.

Jayme, Erik (1995), "Identité culturelle et integration: le droit internationale privé Postmoderne", Recueil des Cours de l'Académie de Droit Internacional de la Haye. Haye, Nijhoff.

Jayme, Erik (2003), "Visões para uma Teoria pós-moderna do Direito Comparado", Cadernos do Programa de Pós-Graduação em Direito da Universidade Federal do Rio Grande do Sul - PPGDir./UFRGS, 1 (1).

Jones, Candace; Hesterly; William S.; Borgatti, Stephen T. (1997), "A General Theory of Network Governance: exchange conditions and social mechanisms", Academy of Management Review, 22 (4), 911-945.

Joshi, Devin; O'Dell, Roni Kay (2013), "Global Governance and Development Ideology: The United Nations and the World Bank on the Left-Right Spectrum", Global Governance, 19, 249-275.

Kingsbury, Benedict; Krisch, Nico; Stewart, Richard B. (2005), "The Emergence of Global Administrative Law”, Law and Contemporary Problems, 68, 15-62.

Klick, Matthew (2011), "Configuring Global Order: Institutions, Processes, and Effects", Global Governance, 17, 557-565.

Kooiman, Jan (1994), Modern Governance. New Government - Society Interactions. London: SAGE Publications.

Kooiman, Jan (2003), Governing as Governance. London: Sage.

Kooiman, Jan Bavinck Maarten; Chuenpagdee, Ratana; Mahon, Robin; Pullin, Roger (2008), "Interactive Governance and Governability: An Introduction", The Journal of Transdisciplinary Environmental Studies, 7 (1), 1-11.

Kymlicka, Will (1995), Multicultural Citizenship: A Liberal Theory of Minority Rights. Oxford: Oxford University Press.

Lange, Hellmuth; Garrelts, Heiko (2008), "Risk Management at the Science-Policy Interface: Two Contrasting Cases in the Field of Flood Protection in Germany", in Nweig, Jeans; VoSS, Jan-Peter; Monstadt, Jochen (ed.), Governance for Sustainable Development. Coping with ambivalence, uncertainty and distributed power. New York: Routledge, 71-87.

Machado, Jónatas E. M. (2013), Direito Internacional: do paradigma clássico ao pós-11 de Setembro. Coimbra: Coimbra Editora. [ $4^{\mathrm{a}}$ ed.]

Marques, Cláudia Lima (2004), Confiança no comércio eletrônico e a proteção do consumidor. São Paulo: Revista dos Tribunais.

Marques, Cláudia Lima (2004), A proteção da parte mais fraca em direito internacional privado e os esforços da CIDIP VII de proteçao dos consumidores. Consultado a 10.06.2014 em: http://www.oas.org/dil/esp/13\%20-\%20lima\%20marques.POR.261-308.pdf.

Marques, Cláudia Lima (2012). "O 'diálogo das fontes' como método da nova teoria geral do direito: um tributo a Erik Jayme", in Marques, Claudia Lima (coord), Diálogo das fontes: do conflito à coordenação de normas do direito brasileiro. São Paulo: Editora Revista dos Tribunais, 17-66.

Mathews, Jessica T. (1997), "Power Shift", Foreign Affairs, 76 (1), 50-66.

Mayer-Schönberger, Viktor; Cukier, Kenneth (2013), Big Data. A Revolution that will transform how we live, work and think. London: John Murray Publishers. 
Mccubbins, Mathew D.; Noll, Roger G.; Weingast, Barry R (1987), "Administrative Procedures as Instruments of Political Control", Journal of Law, Economics, \& Organization, 3 (2), 243-277.

Michalski, Wolfgang; Miller, Riel; Stevens, Barrie (2001), "Governance in the $21^{\text {st }}$ Century: Power in the Global Knowledge Economy and Society", in OECD, Governance in the $21^{\text {st }}$ Century. Paris: OECD, 7-26.

Nicolaidis, Kalypso; Shaffer, Gregory (2005), "Transnational Mutual Recognition Regimes: Governance without Global Government", Law and Contemporary Problems, 68, 263-317.

O’Toole JR.; Laurence, J.; Meier, Kenneth J. (1999), "Modeling the impact of public management: implications of structural context", Journal of Public Administration Research and Theory, 9 (4), 505-526.

Orsini, Amandine; Morin, Jean-Frédéric (2013a), "Regime Complexity and Policy Coherency: Introducing a Co-adjustments Model", Global Governance, 19, 41-51.

Orsini, Amandine; Morin, Jean-Frédéric; Young, Oran (2013b), "Regime Complexes: A Buzz, a Boom, or a Boost for Global Governance?”, Global Governance, 19, 27-39.

Ost, François; van de Kerchove, Michel (2002), "Droit: de la pyramide au réseau? Une introduction", in Ost, François; van de Kerchove, Michel (coord.), De la pyramide au réseau? Pour une théorie dialectique du droit. Bruxelles: Presses des Facultés Universitaires Saint Louis.

Ostrom, Elinor (2010), "Beyond Markets and States: Polycentric Governance of Complex Economic Systems", American Economic Review, 100, 641-672.

Paquet, Gilles (2001), "The New Governance, Subsidiarity, and the Strategic State", in OECD, Governance in the $21^{\text {st }}$ Century. Paris: OECD, 183-214.

Pauwelyn, Joost (2003), Conflict of norms in public international law: bow WTO law relates to other rules of international law. Cambridge: Cambridge University Press.

Perri, 6 (2001), "Governing by Technique: Judgement and the Prospects for Governance of and with Technology", in OECD, Governance in the $21^{\text {st }}$ Century. Paris: OECD, 67-119.

Peters, B. Guy; Pierre, Jon (2006), "Governance, accountability and democratic legitimacy", in Benz, Arthur; Papadopoulos, Yannis (ed.), Governance and Democracy. Comparing national, European and international experiences. Routledge: New York, 27-43.

Provan, Keith G.; Kenis, Patrick (2007), "Modes of Network Governance: Structure, Management, and Effectiveness", Journal of Public Administration Research and Theory, 18, 229-252.

Pureza, José Manuel (2002), "Ordem jurídica, desordem mundial. Um contributo para o estudo do Direito Internacional”, Revista Crítica de Ciências Sociais, 64, 3-40.

Raustiala, Kal; Victor, David G. (2004), "The Regime Complex for Plant Genetic Resources", International Organization, 58, 277-309.

Reinicke, Wolfgang H. (1999), "The Other World Wide Web: Global Public Policy Networks", Foreign Policy, 117, 44-57.

Reinicke, Wolfgang H.; Deng, Francis M. (2000), Critical Choices: The United Nations, Networks \& the Future of Global Governance. Ottawa: International Development Research Centre, Better World Fund, United Nations Foundation. 
Roberts, Nancy (2000), "Wicked Problems and Networks Approaches to Resolution", The International Public Management Review, 1 (1).

Sabel, Charles F.; Zeitlin, Jonathan (2008), "Learning from Difference: The New Architecture of Experimentalist Governance in the European Union", European Law Journal, 14(3), 271-327.

Santos, Boaventura de Sousa (2002), "Os Processos de Globalização", Eurozine. Consultado a 08.06.2014 em: http://www.eurozine.com/articles/2002-08-22-santospt.html

Segura-Serrano, Antonio (2009), "The Transformation of International Law", Jean Monnet Working Paper, 12/09. NYU School of Law.

Slaughter, Anne-Marie (1998), "The Real New World Order", Foreign Affairs, 76 (5), 183-198.

Slaughter, Anne-Marie (2004), A New World Order. Princeton: Princeton University Press.

Stewart, Richard B (2008), "Accountability, Participation, and the Problem of Disregard in Global Regulatory Governance", IILJ International Legal Theory Colloquium Interpretation and Judgment in International Law. NYU Law School.

Tarschys, Daniel (2001), "Wealth, Values, Institutions: Trends in Government and Governance", in OECD, Governance in the $21^{\text {st }}$ Century. Paris: OECD, 27-43.

Teubner, Gunther (2011), "Self-Constitutionalizing TNCs? On the Linkage of 'Private' and 'Public' Corporate Codes of Conduct", Indiana Journal of Global Legal Studies, 18 (2), 17-38.

UE. COM(2001) 428 final (2001), Governança Europeia - Livro Branco. Bruxelas: Comissão das Comunidades Europeias.

UE. COM(2002) 275 final (2002), European Governance: Better Lawmaking. Bruxelas: Comissão das Comunidades Europeias.

Valaskakis, Kimon (2001), "Long-term Trends in Global Governance: From 'Westphalia' to 'Seattle', in OECD, Governance in the $21^{\text {st }}$ Century. Paris: OECD, 45-66.

Viola, F.; Urso, M. (1989), Scienza giuridica e diritto codificato. Giappichelli, Torino. 